\title{
Does Obesity Explain Excess Prevalence of Diabetes Among Mexican Americans? Results of the San Antonio Heart Study
}

\author{
M. P. Stern, S. P. Gaskill, H.P. Hazuda, L. I. Gardner and S. M. Haffner \\ Division of Clinical Epidemiology, Department of Medicine, University of Texas Health Science Center, San Antonio, Texas, USA
}

\begin{abstract}
Summary. Obesity and Type 2 (non-insulin-dependent) diabetes mellitus are common in the Mexican American population. It is not clear whether this is merely a specific instance of the more general phenomenon of excess Type 2 diabetes and obesity among poor people, or whether Mexican Americans have a discrete genetic susceptibility to Type 2 diabetes. The latter consideration arises because Mexican Americans are of mixed native American and European ancestry and native Americans may have a genetic predisposition to Type 2 diabetes which Mexican Americans could share. We studied 936 Mexican Americans and 398 Anglo-Americans randomly selected from three socially and culturally distinct neighbourhoods in San Antonio, Texas. Three categories of obesity lean, average, and obese - were defined using the AngloAmerican distribution of the sum of the triceps and subscapular skinfold. Mexican Americans were two to four times as likely to fall into the obese category as Anglo-Americans, but within categories, the two ethnic groups were closely matched
\end{abstract}

in terms of sum of skinfolds. The prevalence of Type 2 diabetes, however, was significantly greater in Mexican Americans than in Anglo-Americans even when the comparisons were made within the three obesity categories. The summary prevalence ratio, controlling for obesity, was 2.54 for men $(p=0.004)$ and 1.70 for women $(p=0.036)$. Thus, lean Mexican Americans are still at greater risk of Type 2 diabetes than equally lean Anglo-Americans. Conversely, although Type 2 diabetes prevalence increases as expected with increasing obesity in both ethnic groups, obese Anglo-Americans are still relatively protected compared with equally obese Mexican Americans. Plasma glucose was significantly higher in Mexican Americans than in Anglo-Americans even after controlling for obesity. These results indicate that, although obesity contributes to Type 2 diabetes in Mexican Americans, it does not by itself explain the entire excess prevalence rate.

Key words: Type 2 diabetes, obesity, Mexican Americans.
Obesity and Type 2 (non-insulin-dependent) diabetes mellitus are major health problems in the Mexican American population [1-3] as in many other low income populations [4]. In addition to poverty as a predisposing factor Mexican Americans could also have a discrete genetic predisposition to Type 2 diabetes; about a third of the Mexican American gene pool is derived from native American sources $[5,6]$ and since the latter may have a genetic predisposition to Type 2 diabetes [7], Mexican Americans could share this, albeit in a diluted form. The San Antonio Heart Study is a comprehensive epidemiological investigation of Type 2 diabetes and cardiovascular risk factors in Mexican Americans and Anglo-Americans living in San Antonio, Texas. (Anglo-American is the term commonly used in the Southwest to designate non-Hispanic Caucasoids.) The present analysis was undertaken to ascertain whether the excess rate of Type 2 diabetes in Mexican Americans could be entirely attributed to their high prevalence of obesity, or whether it is necessary to invoke ad- ditional factors (e.g., genetic, nutritional) to explain the excess.

\section{Subjects and Methods}

Subjects ( 25 to 64 years of age) were randomly sampled from three San Antonio neighbourhoods: low income ('barrio'); middle-income (transitional); and high-income (suburbs). In the 'barrio' only Mexican Americans were sampled, but in the other two neighbourhoods, approximately equal numbers of Mexican Americans and AngloAmericans were sampled. A detailed description of our sampling procedures has been published [8]. Informed consent was obtained before participation.

The study design included an initial home interview followed by a medical examination in a mobile clinic. The sample sizes and response rates in the three neighbourhoods are shown in Table 1. Field work was carried out from October, 1979 to August, 1981.

Ethnic classification was performed using an algorithm which considered interviewer identification, Spanish or non-Spanish surname of both parents (maiden-name in the case of the mother), and stated ethnicity of all four grandparents. Non-Mexican American 
Table 1. Sample size and response rates

\begin{tabular}{|c|c|c|c|}
\hline & \multicolumn{3}{|c|}{ Neighbourhood } \\
\hline & Barrio & Transitional & Suburbs \\
\hline Eligible for home interview & 849 & 496 & 884 \\
\hline Number interviewed & 756 & 383 & 786 \\
\hline Response rate & $89.0 \%$ & $77.2 \%$ & $88.9 \%$ \\
\hline Eligible for medical & & & \\
\hline examination ${ }^{\mathrm{a}}$ & 720 & 379 & 768 \\
\hline Number examined & 496 & 285 & 642 \\
\hline Response rate & $68.9 \%$ & $75.2 \%$ & $83.6 \%$ \\
\hline
\end{tabular}

${ }^{a}$ Reasons for loss of eligibility between the home interview and the medical examination included moving out of the area and discovery of pregnancy after completion of the home interview.

Table 2. Diabetic patients according to plasma glucose level and therapy

\begin{tabular}{lcl}
\hline & $\begin{array}{l}\text { Patients meeting } \\
\text { the National } \\
\text { Diabetes Data } \\
\text { Group criteria }\end{array}$ & $\begin{array}{l}\text { Patients not } \\
\text { meeting the } \\
\text { National Diabetes } \\
\text { Data Group criteria }\end{array}$ \\
\hline $\begin{array}{l}\text { Mexican Americans } \\
\text { Newly discovered } \\
\text { Previously diagnosed }\end{array}$ & 50 & - \\
$\quad \begin{array}{l}\text { On dietary } \\
\text { treatment only }\end{array}$ & 12 & \\
$\begin{array}{l}\text { On oral agents } \\
\text { On insulin }\end{array}$ & 26 & 36 \\
$\begin{array}{l}\text { Anglo-Americans } \\
\text { Newly discovered }\end{array}$ & 13 & 6 \\
Previously diagnosed & 6 & 0 \\
$\quad$ On dietary & & - \\
treatment only & 3 & 12 \\
On oral agents & 1 & 2 \\
On insulin & 2 & 0 \\
\hline Total & 113 & 56 \\
\hline
\end{tabular}

Hispanics and offspring of inter-ethnic marriages (91 individuals in all) were excluded from the analyses.

Anthropometric measurements (stature, weight, and skinfold thicknesses) were made with the participant wearing an examining gown after removal of shoes and upper garments. The triceps skinfold was measured directly posterior over the right triceps muscle and the subscapular skinfold was measured just below the inferior angle of the right scapula. A Lange skinfold caliper (Cambridge Scientific Industries, Cambridge, Maryland, USA) was used and the average of three readings, each made to the nearest $0.5 \mathrm{~mm}$, was taken as the measurement for each skinfold.

Two-day training sessions in skinfold measurements were held before data collection and at 6-monthly intervals thereafter. During the first two training sessions, replicate measurements were made on groups of five subjects to assess inter-observer variation. The technical errors of measurement (the square root of the sum of the squared differences of replicate measurements divided by twice the number of pairs) were 2.9 and $3.6 \mathrm{~mm}$ for the triceps measurement and 2.6 and $2.9 \mathrm{~mm}$ for the subscapular measurement. These error estimates are larger than reported for the Health Examination Survey which were $1.9 \mathrm{~mm}$ for the triceps and $1.5 \mathrm{~mm}$ for the subscapular skinfold [9]. The latter error estimates, however, were made on youths, age 12-17 years, whereas our sample consisted of adults, with larger mean skinfold thicknesses. When our errors are expressed as a percentage of the mean for the measurement itself (i. e., as a coefficient of variation), they compare favourably with the Health Examination Survey errors $(16.7 \%$ for the triceps skinfold and $15.0 \%$ for the subscapular skinfold in our study versus $15.5 \%$ and $15.4 \%$ in the Health Examination Survey).

Fasting blood specimens were obtained after a 12 -h overnight fast; subsequent specimens were obtained 1 and $2 \mathrm{~h}$ after ingestion of a $75-\mathrm{g}$ glucose-equivalent carbohydrate load $(204 \mathrm{ml}$ of Glucola, Ames, Elkhart, Indiana, USA). Plasma glucose concentrations were measured using an Abbott Bichromatic Analyzer (Abbot Laboratories, South Pasadena, California, USA). Diabetes was diagnosed according to the new criteria recommended by the National Diabetes Data Group [10]: fasting plasma glucose $\geqslant 7.8 \mathrm{mmol} / 1$ or both 1 and $2 \mathrm{~h}$ values $\geqslant 11.1 \mathrm{mmol} / \mathrm{l}$. As shown in Table 2, 113 individuals met these criteria. These individuals will be referred to as "hyperglycaemic'. Also shown in Table 2 are an additional 56 individuals who stated that they had diabetes, but who did not meet the National Diabetes Data Group criteria at the time of our survey. Many of these are no doubt genuine diabetics whose plasma glucose concentrations were well controlled at the time of the survey. Some, however, may have been misdiagnosed, particularly considering that the new National Diabetes Data Group criteria are stricter than previous criteria. We therefore analyzed our data using two definitions of diabetes: the first includes all cases listed in Table 2 and is thus highly sensitive, though relatively non-specific. The second, more conservative definition includes only the 113 hyperglycaemic cases and is thus less sensistive, but highly specific. Since we wished to restrict the analyses to Type 2 diabetes, the 15 insulin-taking patients shown in Table 2 were excluded from all analyses. We recognize that some of these cases may have had Type 2 diabetes despite their having been treated with insulin; in view of their small number, however, their exclusion has a minimal impact on the analyses.

Three categories of obesity were defined on the basis of the distribution of the sum of the triceps and subscapular skinfolds of the Anglo-American population. The Anglo-American skinfold distribution was divided into equal thirds; the lowest third was labelled 'lean', the middle third, 'average', and the upper third, 'obese'. This procedure was carried out separately for the two sexes. The reason we have chosen to base our obesity categories on skinfold measurements is that, since different ethnic groups may differ in bone and muscle mass, similar weight for height does not guarantee similar degrees of obesity. Nevertheless, we also analyzed our data using obesity categories based on relative weight (actual/ideal weight), and the results were essentially identical to those reported in this paper.

The distribution of Mexican American participants across the three obesity categories was tested using a $\chi^{2}$ statistic under the null hypothesis that a third of the participants should have fallen into each category. Summary prevalence ratios, controlling for obesity, were computed using equation 17.11 in Kleinbaum et al. [11]. This method is analogous to the Mantel-Haenszel odds ratio. Plasma glucose values were $\log$-transformed to reduce skewness. The resulting distributions appeared to be normal or nearly normal without evidence of bimodality. The log-transformed values were analyzed by multiple linear regression using the Biomedical Computer Programs statistical package with age entered as a continuous covariate and the 6 ethnicobesity categories entered as 'dummy' or 'group' variables. These analyses were performed separately for the two sexes. The logarithms were then back-transformed to natural units and the age-adjusted mean \pm SEM are presented in Tables 7 and 8 .

\section{Results}

Table 3 shows that, within obesity categories, Mexican Americans are somewhat younger than Anglo-Americans, although these differences are statistically significant in only two of the six comparisons. These differences, however, are in a direction which strengthens rather than weakens the arguments to be presented later with respect to ethnic differences in Type 2 diabetes 
Table 3. Age and age-adjusted sum of skinfolds of Mexican Americans and Anglo-Americans according to category of obesity

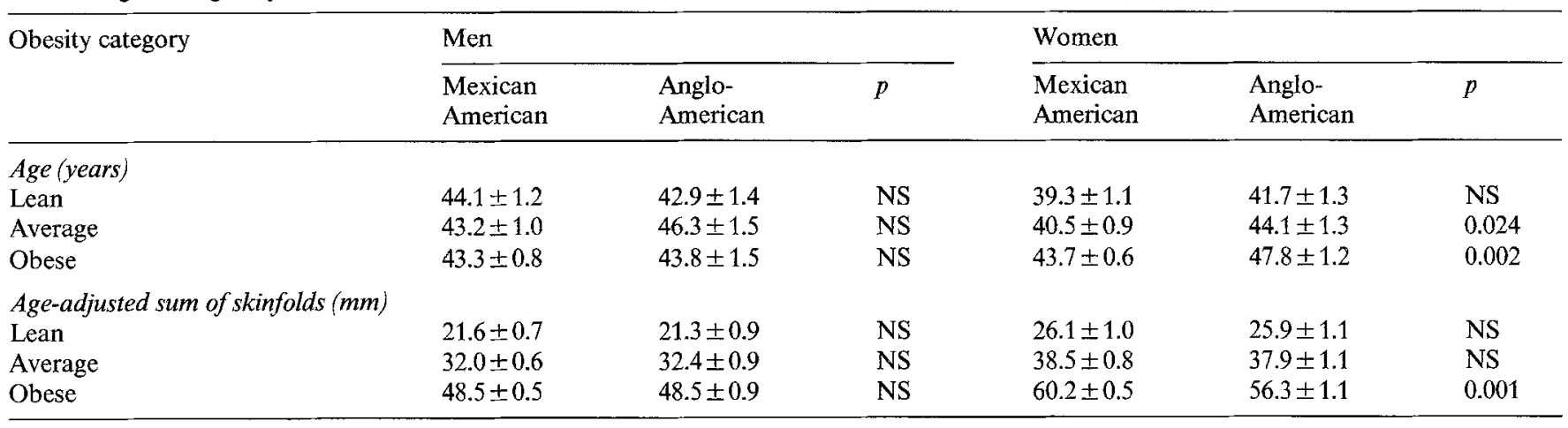

Results expressed as mean $\pm \mathrm{SEM} ; \mathrm{NS}=$ not significant

Table 4. Distribution of Mexican Americans and Anglo-Americans according to category of obesity

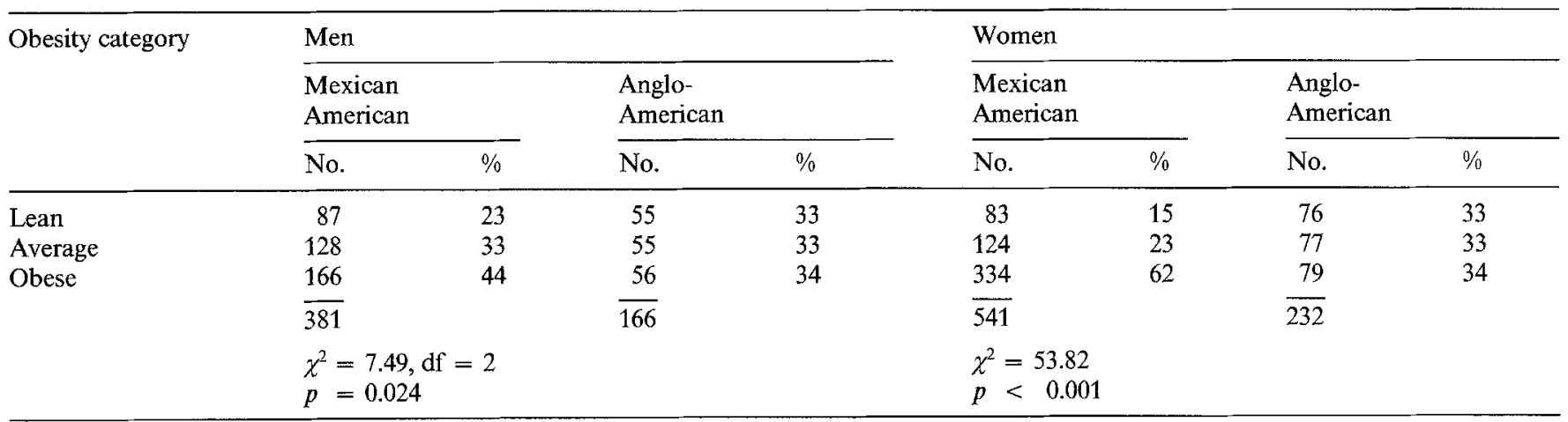

Table 5. Prevalence of Type 2 diabetes (total group) in Mexican Americans and Anglo-Americans according to category of obesity

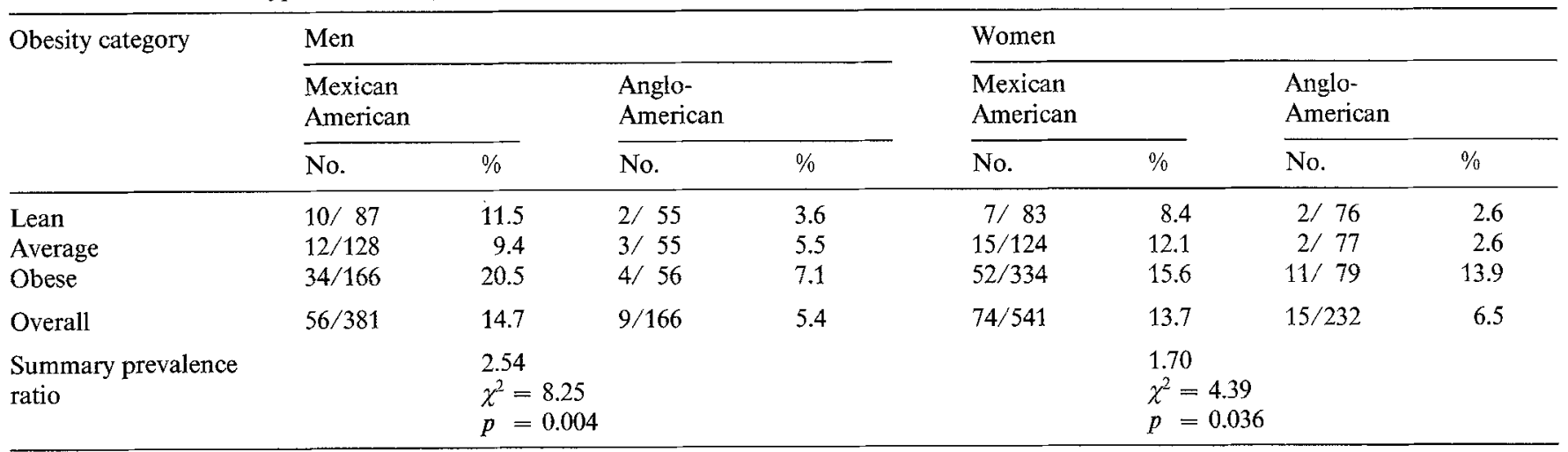

prevalence. Moreover, in the comparisons of plasma glucose concentrations, these variables have been ageadjusted by multiple linear regression, further lessening the impact of the age differential.

The age-adjusted sums of skinfolds according to sex, ethnic group, and category of obesity are also shown in Table 3. Except for women in the obese category, the mean sums of skinfolds within each category of obesity were nearly identical in the two ethnic groups. This excellent matching enables us to compare prevalence of Type 2 diabetes and glucose tolerance in Mexican Americans and Anglo-Americans who are very closely matched for degree of obesity. Since these data are cross-sectional, the obesity distributions may be influenced by spontaneous weight loss among the prevalent cases of diabetes resulting from their disease. However, in that this phenomenon would probably affect the two ethnic groups similarly, the validity of the ethnic comparisons seems unlikely to be seriously affected.

The distribution of the two ethnic groups according to category of obesity is shown in Table 4. Anglo-American men and women are equally divided among the three categories (by definition). Mexican American men, on the other hand, were twice as likely to be in the obese category as the lean, and Mexican American 
Table 6. Prevalence of Type 2 diabetes (hyperglycaemic group) in Mexican Americans and Anglo-Americans according to category of obesity

\begin{tabular}{|c|c|c|c|c|c|c|c|c|}
\hline Obesity category & \multicolumn{4}{|l|}{ Men } & \multicolumn{4}{|l|}{ Women } \\
\hline Lean & $6 / 87$ & 6.9 & $1 / 55$ & 1.8 & $2 / 83$ & 2.4 & $0 / 76$ & 0 \\
\hline Average & $9 / 128$ & 7.0 & $2 / 55$ & 3.6 & $9 / 124$ & 7.3 & $0 / 77$ & 0 \\
\hline $\begin{array}{l}\text { Summary prevalence } \\
\text { ratio }\end{array}$ & & $\begin{array}{l}4.02 \\
\chi^{2}= \\
p=\end{array}$ & & & & $\begin{array}{l}2.41 \\
\chi^{2}= \\
p=\end{array}$ & & \\
\hline
\end{tabular}

Table 7. Age-adjusted plasma glucose concentrations in Mexican Americans and Anglo-Americans according to category of obesity

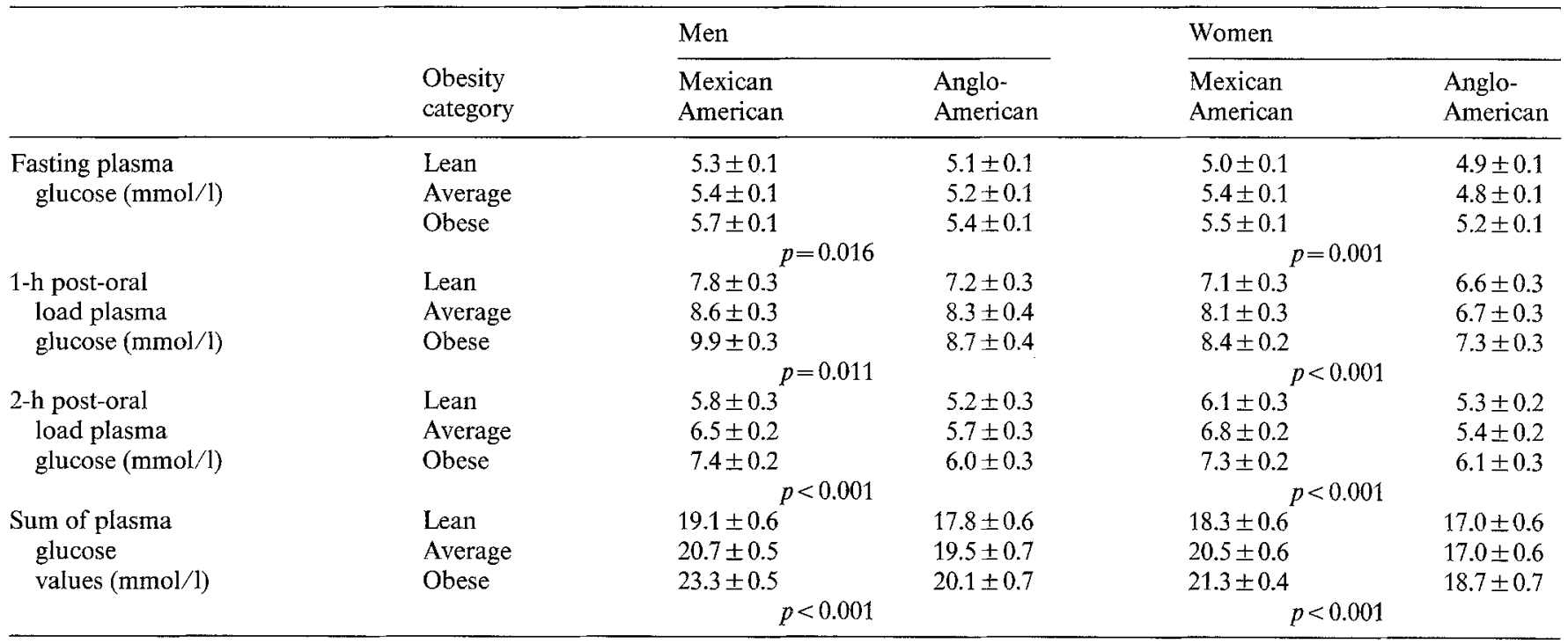

Results expressed as mean $\pm \mathrm{SEM}$

women were four times as likely to be in the obese category as the lean. Both of these departures from the equal thirds distribution were highly significant.

The prevalence of Type 2 diabetes according to sex, ethnic group, and category of obesity is shown in Table 5. (In this Table all 154 non-insulin-taking diabetic patients from Table 2 are included.) As expected, the prevalence of Type 2 diabetes rises with increasing degrees of obesity in both sexes and both ethnic groups. However, for both sexes, Mexican Americans have a substantially higher prevalence of Type 2 diabetes than Anglo-Americans within each category of obesity. The summary prevalence ratio, controlling for obesity, was 2.54 for men $(p=0.004)$ and 1.70 for women $(p=0.036)$.

The prevalence of Type 2 diabetes using only the 98 non-insulin-taking hyperglycaemic cases is shown in Table 6. Again, the prevalence of diabetes increases with increasing obesity, but Mexican Americans have higher prevalence than Anglo-Americans even within obesity categories. The summary prevalence ratio, controlling for obesity, was 4.02 for men $(p=0.003)$ and 2.41 for women $(p=0.020)$. Thus, using this more con- servative definition for Type 2 diabetes, an even greater excess was noted in Mexican Americans after controlling for obesity.

The age-adjusted means ( \pm SEM) of the fasting and of the 1 and $2 \mathrm{~h}$ post-oral glucose load plasma glucose concentrations, and the sum of the three plasma glucose concentrations according to sex, ethnic group, and category of obesity are shown in Table 7. As expected, plasma glucose concentrations, whether fasting or post-glucose load, rise with increasing degrees of obesity in both sexes and in both ethnic groups. Within obesity categories, however, Mexican Americans consistently have higher glucose concentrations than Anglo-Americans. The $p$-values shown in the Table refer to the pooled ethnic contrasts. These are in every case statistically significant indicating that, ever after having taken into account the ethnic differences in obesity, Mexican Americans have significantly higher plasma glucose concentrations than Anglo-Americans.

Ethnic comparisons of the plasma glucose values with all 169 diabetic patients having been removed from the study population are shown in Table 8 . In general 
Table 8. Age-adjusted plasma glucose concentrations in Mexican Americans and Anglo-Americans according to category of obesity (excluding diabetic patients)

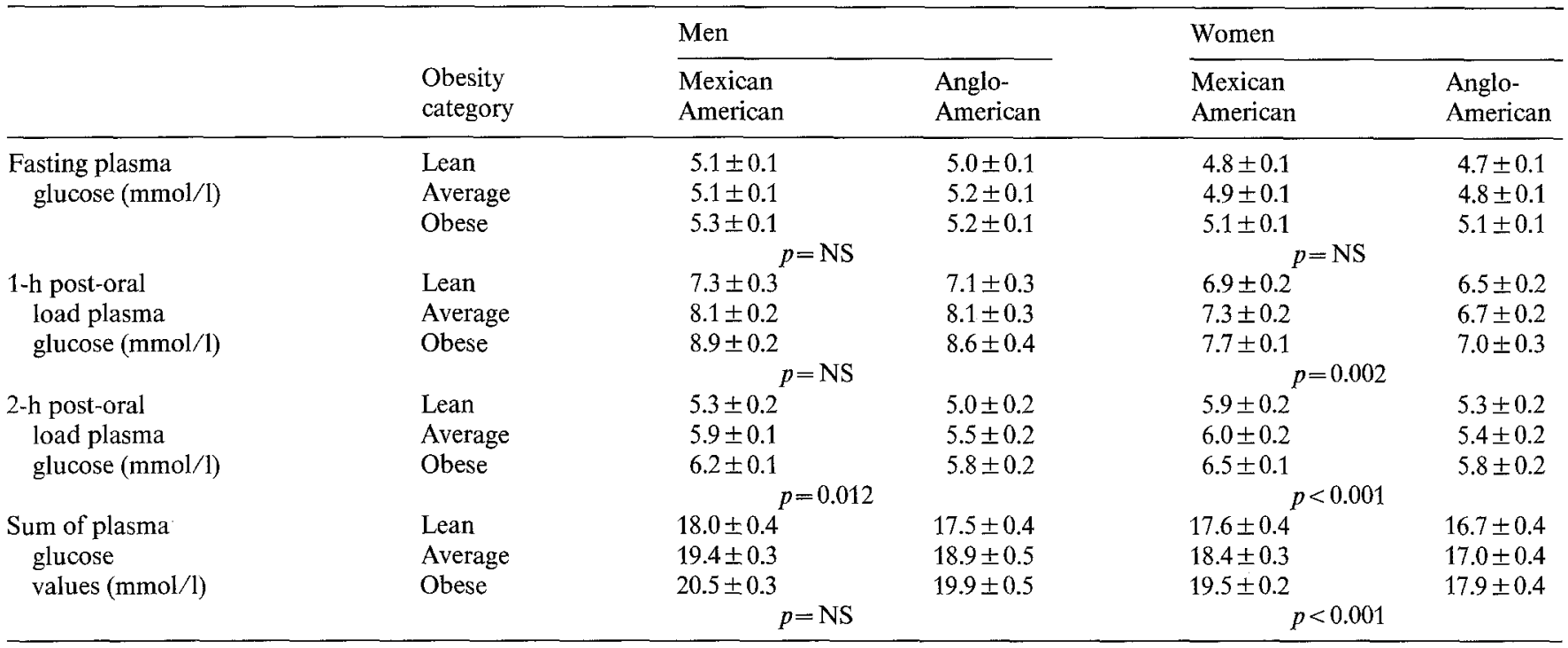

Results expressed as mean $\pm \mathrm{SEM}$; NS = not significant

the ethnic differences are much less than in Table 7, although some of the comparisons are still statistically significant, particularly in women. The results do suggest, however, that glucose values are modestly higher in non-diabetic Mexican Americans than in non-diabetic Anglo-Americans of similar degree of obesity.

\section{Discussion}

There is now a large literature on the 'epidemic' of Type 2 diabetes in populations which to varying degrees have undergone changes from a 'traditional' to a 'western' lifestyle [4, 7, 12-14]. Increasing rates of obesity are a consistent feature of this 'westernization' process and, in fact, West has suggested that this change is by itself a sufficient explanation for the rising diabetes rates in these populations [4]. On the other hand, Kawate et al. have reported that, even after matching for obesity, 'westernized' Japanese living in Hawaii have higher rates of diabetes than more 'traditional' Japanese living in Japan [15]. Since these two population groups are presumed to be genetically similar, these results imply that environmental factors other than those which lead to obesity also contribute to the rising prevalence of diabetes in Japanese Americans. Further evidence that obesity alone cannot explain all population differences in prevalence of diabetes comes from studies reported by Jackson $[16,17]$ : diabetes prevalence was higher in the South African Indian and 'Cape Coloured' populations than in South African Whites and Bantus even though obesity was more common in the latter two groups.

The results of the present study indicate that Mexican Americans are another population in which obesity is not by itself an adequate explanation for excess Type 2 diabetes prevalence. Thus, the lean among them are still at greater risk of Type 2 diabetes than equally lean Anglo-Americans. Conversely, although Type 2 diabetes prevalence increases as expected with increasing obesity in both ethnic groups, obese Anglo-Americans are still relatively protected compared with equally obese Mexican Americans.

Both genetic and environmental factors could contribute to explaining Type 2 diabetes prevalence in those populations whose excess prevalence exceeds that which can be attributed to obesity alone. In addition to obesity, increasing consumption of fat and simple carbohydrate, decreasing consumption of complex carbohydrate, and adoption of a sedentary lifestyle are prominently mentioned features of the 'westernization' process. As yet, however, there is no conclusive evidence that any of these environmental factors directly contributes to Type 2 diabetes over and above its contribution to obesity. It is also possible that certain populations have an unusual concentration of 'diabetes susceptibility genes'. We have recently presented evidence indicating heterogeneity in native American genetic admixture among San Antonio Mexican Americans and have shown that Type 2 diabetes prevalence in this population parallels the degree of native American genetic admixture [18]. It is hoped that further study of this population will clarify the role of genetic and environmental factors in the pathogenesis of diabetes.

Acknowledgements. This research was supported by a grant from the National Heart, Lung, and Blood Institute (HL 24799). The authors also wish to acknowledge the excellent computer programming assistance of Mr. P.Comeaux. 


\section{References}

1. Stern MP, Haskell WL, Wood PD, Osann KE, King AB, Farquhar JW (1975) Affluence and cardiovascular risk factors in MexicanAmericans and other whites in three northern California communities. J Chron Dis 28: 623-636

2. Stern MP, Gaskill SP (1978) Secular trends in ischemic heart disease and stroke mortality from 1970 to 1976 in other whites and Spanish-surnamed individuals in Bexar County, Texas. Circulation 58: $537-543$

3. Stern MP, Gaskill SP, Allen CR Jr, Garza V, Gonzales JL, Waldrop RH (1981) Cardiovascular risk factors in Mexican Americans in Laredo, Texas. 1. prevalence of overweight and diabetes and distribution of serum lipids. Am J Epidemiol 113: 546-555

4. West KM (1978) Epidemiology of diabetes and its vascular lesions. Elsevier, New York

5. Reed TE (1974) Ethnic classification of Mexican Americans. Science 285: 283

6. Gottlieb K, Kimberling WJ (1979) Admixture estimates for the gene pool of Mexican Americans in Colorado. Am J Phys Anthropol 50: 44 (Abstract)

7. Bennett PH, Rushforth NB, Miller M, LeCompte PM (1976) Epidemiologic studies of diabetes in the Pima Indians. Recent Prog Horm Res 32: 333-376

8. Stern MP, Pugh JA, Gaskill SP, Hazuda HP(1982) Knowledge, attitudes, and behavior related to obesity and dieting in Mexican Americans and Anglos: the San Antonio Heart Study. Am J Epidemiol 115: 917-928

9. Johnston FE, Hamill PVV, Lemeshow S (1974) Skinfold thickness of youths, 12-17 years, United States. Vital and Health Statistics, Series 11, No. 132. National Center for Health Statistics, US Dept of Health, Education, and Welfare. DHEW Publication No (HRA) 74-1614. Rockville, Maryland, USA

10. National Diabetes Data Group (1979) Classification and diagnosis of diabetes mellitus and other categories of glucose intolerance. Diabetes 28: 1039-1057
11. Kleinbaum DG, Kupper LL, Morgenstern H (1972) Epidemiologic research: principles and quantitative methods. Lifetime Learning Publications, London, p 345

12. West KM, Kalbfleisch JM (1971) Influence of nutritional factors on prevalence of diabetes. Diabetes 20: 99-108

13. West KM (1974) Diabetes in American Indians and other native populations of the New World. Diabetes 23: 841-855

14. Wicking J, Ringrose H, Whitehouse S, Zimmet P (1981) Nutrient intake in a partly westernized isolated Polynesian population: the Funafuti survey. Diabetes Care 4: 92-95

15. Kawate R, Yamakido M, Nishimoto $Y$, Bennet PH, Hamman RF, Knowler WC (1979) Diabetes mellitus and its vascular complications in Japanese migrants on the island of Hawaii. Diabetes Care 2: $161-170$

16. Jackson WPU (1972) Diabetes and related variables among the five main racial groups in South Africa: comparisons from population studies. Postgrad Med J 48: 391-398

17. Jackson WPU (1978) Epidemiology of diabetes in South Africa. Advances in Metab Disorders 9: 111-146

18. Stern MP, Relethford JH, Ferrell RE, Gaskill SP, Hazuda HP, Haffner SM, Gardner LI (1982) Diabetes and genetic admixture in Mexican Americans: the San Antonio Heart Study. Diabetes 31 (suppl2): $45 \mathrm{~A}$

Received: 7 April 1982

and in revised form: 16 November 1982

Dr. M.P.Stern

Department of Medicine

Division of Clinical Epidemiology

University of Texas Health Science Center at San Antonio

7703 Floyd Curl Drive

San Antonio, Texas, 78248, USA 